Fernanda de Castro Nakamura ${ }^{1}$

Nathália Melazi Caobianco ${ }^{1}$

\title{
A JUDICIALIZAÇÃO DO DIREITO À SAÚDE EM UMA PERSPECTIVA COMPARADA: BRASIL E COLÔMBIA
}

The judicialization of the right to health in a comparative perspective: Brazil and Colombia

${ }^{1}$ Faculdade de Ciências Humanas e Sociais. Universidade Estadual Paulista “Júlio de Mesquita Filho". Franca/SP, Brasil.

Correspondência: Fernanda de Castro Nakamura. E-mail: fernandanakamuraadv@gmail.com

Recebido: 13/12/2017. Revisão: 19/11/2018. Aprovado: 03/01/2019. 


\section{RESUMO}

O presente artigo tem como objetivo estudar, em perspectiva comparada, a judicialização da saúde no Brasil e na Colômbia. A análise comparativa justifica-se pela proximidade histórica, política e social existente entre os dois países, principalmente no que se refere à colonização e aos marcos de subdesenvolvimento, bem como pela existência de dados específicos consolidados nesses países. Dessa forma, por meio de uma revisão da literatura sobre o tema e da análise de dados nas bases governamentais de ambos os países, pontuaram-se as principais diferenças no tratamento dado à saúde e os efeitos que o controle judicial das políticas públicas tem sobre a organização política e administrativa dessas sociedades. Como conclusão, verificou-se que tanto Brasil como Colômbia padecem de uma gestão de saúde que permita incluir esse direito fundamental no projeto de desenvolvimento socioeconômico das agendas governamentais.

\section{Palavras-Chave}

Judicialização da Saúde; Sistema de Saúde Brasil; Sistema de Saúde Colômbia.

\section{ABSTRACT}

This article aims to study the judicialization of health in Brazil and Colombia, from a comparative perspective. The comparative analysis is justified by the historical, political and social affinities existing between these two countries, mainly in relation to colonization and underdevelopment, and for there are consolidated data in both countries, specifically. In this way, through the review of literature on the theme and the analysis of government databases of both countries, the main differences in the management of health care were pointed out, as well as the effects that judicial control over public policies exert on the political and administrative organization of these societies. In the conclusion, it was established that both countries lack the management of health that would enable the inclusion of this fundamental right in the socio-economic development projects of these governments agendas.

\section{Keywords}

Health Judicialization; Health System in Brazil; Health System in Colombia. 


\section{Introdução}

Recentemente, quase todos os países da América Latina passaram por reformas no âmbito da prestação de serviços públicos, em especial na área da saúde. Dentre os diversos fatores estruturais e políticos geradores de tais mudanças, não se pode olvidar da transição entre o modelo vigente até 1970/1980, vinculado às políticas desenvolvimentistas, e a necessidade de um ajuste econômico de caráter liberal que se impôs nos anos seguintes, nas décadas de 1980/1990.

A liberalização da economia e os processos de mudança macroeconômica, impostos pelas organizações financeiras internacionais, pregaram a redução das funções do Estado e incentivaram uma reforma intensa nas políticas sociais, sobretudo nos países latino-americanos. $\mathrm{Na}$ área da saúde, na maior parte da América Latina, com exceção do Brasil, os novos modelos caracterizaram-se pela descentralização, pela introdução da política de mercado e pelo estímulo à participação privada, diminuindo o âmbito de atuação do Estado e os custos dos serviços públicos.

É importante notar que, apesar de não terem sido homogêneas e simultâneas em todos os países, as reformas seguiram uma mesma agenda de privatização e seletividade, buscando reduzir o tamanho do Estado.

Embora longe da homogeneidade, o fato é que os países da América Latina se aproximam em razão de fatores históricos, políticos e sociais. Trata-se de nações colonizadas pela Espanha ou por Portugal, marcadas pelo subdesenvolvimento, pela industrialização tardia e pela dependência de recursos internacionais. Ademais, apresentam inúmeros problemas sociais e políticos e adotam, em sua maioria, o sistema judicial da civil law, de origem romana.

Dessa forma, o presente artigo busca abordar a diversidade nos mecanismos de proteção da saúde na América Latina, o que será feito através de estudo comparativo entre a Colômbia e o Brasil, destacando as principais diferenças entre os sistemas de saúde adotados e como se desenvolve o fenômeno da judicialização da saúde em ambas as nações.

Para tanto, foi realizada uma revisão da literatura sobre o tema, baseada em artigos e autores que tratam sobre a judicialização da saúde e direitos sociais fundamentais, bem como uma análise dos dados disponíveis nos sítios eletrônicos de órgãos governamentais de ambos os países, a fim de possibilitar uma análise comparativa que evidencie o desenvolvimento da judicialização da saúde.

A escolha dos dois países deve-se ao fato de existirem dados consolidados sobre o direito à saúde e sua judicialização, o que permitiu promover o estudo comparativo e vislumbrar a dinâmica do controle judicial das políticas públicas na América Latina. 
Entender como o direito à saúde é tratado em um país vizinho, cujas dificuldades se aproximam das brasileiras, é um mecanismo para refletir de forma mais ampla sobre causas e possíveis soluções para as questões sanitárias e de controle judicial de políticas públicas que se apresentam com intensidade no Brasil.

\section{A especificação do direito à saúde no âmbito internacional}

O conceito de saúde mudou muito ao longo do tempo, mas hoje prevalece aquele previsto pela Constituição da Organização Mundial da Saúde (OMS), de $1946^{1}$, cujo preâmbulo preceitua que:

A saúde é um estado de completo bem-estar físico, mental e social, e não consiste apenas na ausência de doença ou de enfermidade. [...] Os Governos têm responsabilidade pela saúde dos seus povos, a qual só pode ser assumida pelo estabelecimento de medidas sanitárias e sociais adequadas.

Posteriormente, como desdobramento dos principais assuntos incluídos na Declaração Universal dos Direitos Humanos de 1948, foram apresentados o Pacto Internacional sobre Direitos Econômicos, Sociais e Culturais, adotado pela XXI Sessão da Assembleia Geral das Nações Unidas, em 19 de dezembro de 1966, e o Protocolo de San Salvador, de 1969.

Os documentos internacionais trazem, nesse âmbito, a necessidade de comprometimento por parte dos Estados e a cooperação para que o direito à saúde seja garantido de forma plena. Por serem signatários desses documentos aqui apresentados, Brasil e Colômbia têm o compromisso de prover o direito à saúde por meio de políticas públicas, que devem fazer parte da agenda governamental como instrumentos para promover o desenvolvimento socioeconômico da nação.

Dessa forma, a saúde é tratada em ambos os países como um direito social fundamental que deve ser garantido a todos os seus cidadãos de forma plena e universal. No caso da Colômbia, especificamente, Arango $^{2}$, ao falar sobre a promoção do direito à saúde, dispõe que, em vista de uma Constituição Democrática, Social e de Direito como é a colombiana, há uma dificuldade de se estabelecer se o direito deve se alinhar aos preceitos internacionais que primam pelo direito à saúde inerente ao

\footnotetext{
${ }^{1}$ ORGANIZAÇÃO DAS NAÇÕES UNIDAS - ONU. Assembleia Geral das Nações Unidas. Constituição da Organização Mundial da Saúde (OMS/WHO) - 1946. Disponível em: http://www.direitoshumanos.usp. br/index.php/OMS-Organiza\%C3\%A7\%C3\%A3o-Mundial-da-Sa\%C3\%BAde/constituicao-da-organizacaomundial-da-saude-omswho.html. Acesso em: jan. 2016.

${ }^{2}$ ARANGO, Rodolfo. Promoción de los derechos sociales constitucionales por via de protección judicial. El Outro Derecho, ILSA, Bogotá-D.C., Colombia, n. 28, jul. p. 104-122, 2002. Disponível em: https:// s3.amazonaws.com/academia.edu.documents/34888817/PROMOCION_D_ELOS_DERECHOS_ SOCIALES_CONSTITUCIONALES.pdf?AWSAccessKeyId=AKIAIWOWYYGZ2Y53UL3Ä\&Expires=1541515415 \&Signature=K6b\%2BPyVSbTf1poOPkDMwcNwPUgY\%3D\&response-content-disposition=inline $\% 3 B \% 20 \mathrm{fi}-$ lename\%3DPromocion_de_los_derechos_sociales_const.pdf. Acesso em: fev. 2017.
} 
ser humano, ou se ele deve ser interpretado de forma sistêmica, o que muitas vezes pode acarretar a dificuldade de aplicação e efetivação desse direito ${ }^{3}$.

Já no caso brasileiro, a Constituição Federal de $1988(\mathrm{CF} / 88)^{4}$ foi o marco da redemocratização no país, que culminou com o redimensionamento dos direitos sociais, sobretudo o direito à saúde, que passou a fazer parte do projeto de desenvolvimento socioeconômico do país. Assim, o direito à saúde é universal e dependente de políticas sociais e econômicas para se concretizar. A problemática, no caso brasileiro, reside na efetivação plena desse direito, tendo em vista que as políticas sociais dependem da atuação política para serem concretas ${ }^{5}$.

Levando em consideração a reflexão do direito à saúde no cenário internacional, com enfoque no Brasil e na Colômbia, objeto deste estudo, os tópicos a seguir expõem como o direito à saúde é visto nesses dois países e de que forma eles acabam por demandar uma posição mais ativa da população e do Poder Judiciário para sua implementação.

\section{O sistema de saúde da Colômbia}

Seguindo a tendência dos demais países sul-americanos nas décadas de 1980 e 1990 e os ditames das entidades internacionais, a Colômbia criou, por meio da Lei n. 100 de 1993, um sistema obrigatório de seguro de saúde, o Sistema General de Seguridad Social e Salud (SGSSS), arquitetado com participação público-privada. Trata-se de um modelo de política neoliberal que promoveu a mercantilização da saúde, caracterizado por uma estrutura descentralizada e por funções bem especializadas/delimitadas. O objetivo do sistema era alcançar maiores níveis de eficiência e qualidade na prestação pública de saúde.

Além da mencionada lei pertinente ao direito à saúde, cabe destacar que os direitos sociais na Colômbia são marcados pela necessidade de corrigir injustiças no acesso aos direitos por seus cidadãos, causadas pela desigualdade social presente no país.

A esse respeito, a dificuldade de implementação dos direitos sociais na Colômbia deve-se ao fato de que não há um conceito definido de realização da pessoa humana para o desenvolvimento socioeconômico do país. Em outras palavras, não há preocupação governamental em concretizar direitos sociais, o que consequentemente leva à intensificação da judicialização

\footnotetext{
${ }^{3} \mathrm{O}$ autor cita como entraves à aplicação do direito na Colômbia, a questão da comprovação da pobreza, a conjuntura política e os programas governamentais. ARANGO, Rodolfo. op. cit., p. 118.

${ }^{4}$ BRASIL. Constituição da República Federativa do Brasil de 1988. Disponível em: http://www.planalto.gov. br/ccivil_03/constituicao/constituicaocompilado.htm. Acesso em: 09 set. 2019.

${ }^{5}$ PAIVA, Carlos Henrique Assunção; TEIXEIRA, Luiz Antonio. Reforma sanitária e a criação do Sistema Único de Saúde: notas sobre contextos e autores. História, Ciências, Saúde, Manguinhos, Rio de Janeiro, v. 21, n. 1, p. 15-35, jan./mar. 2014. Disponível em: http://www.scielo.br/pdf/hcsm/v21n1/0104-5970hcsm-21-1-00015.pdf. Acesso em: dez. 2015.
} 
O modelo de reforma introduzido pela Lei n. 100/1993 na Colômbia foi o plural, ou "pluralismo estruturado", uma vez que se baseia em mecanismos de mercado, mas com liberdade limitada pela intervenção do governo, responsável por supervisionar e regular o sistema ${ }^{6}$.

A referida lei foi um marco na política sanitária do país, estabelecendo as principais diretrizes do novo modelo e vigorando até hoje, com diversas modificações posteriores. Ela eliminou a relação direta entre paciente e médico, criando instituições intermediárias responsáveis por organizar e garantir a filiação e a prestação de saúde aos segurados, chamadas de Entidades Promotoras de Saúde (EPS). Na prática, isso promoveu uma privatização da saúde, já que, embora possam ser públicas ou privadas, a maioria dessas entidades é do setor privado.

Esse avanço da mercantilização dos serviços de saúde na Colômbia promovido pela Lei n. 100/1993 resultou na visualização de uma tensão permanente entre a efetividade do direito à saúde e a lógica capitalista, que contribui para um mercado de saúde orientado pelo lucro sem se atentar, portanto, aos princípios da equidade e da qualidade ${ }^{7}$.

Sobre as EPS, destaca-se também que elas têm autonomia para decidir entre prestar diretamente o serviço de saúde a seus filiados e contratar instituições especializadas, as Instituições Prestadoras de Saúde (IPS). Assim, o sistema de saúde colombiano é composto por três pilares: o Estado, na figura do Ministerio de Saludy Protección Social, cuja função é regular e fiscalizar toda a complexa estrutura criada; as Entidades Promotoras de Saúde (EPS), responsáveis por garantir a prestação dos serviços estabelecidos nos Plans Obligatorios de Salud (POS) a seus afiliados; e as Instituições Prestadoras de Saúde (IPS), que são os hospitais, clínicas e laboratórios responsáveis pelo efetivo atendimento médico ${ }^{8}$.

Segundo o artigo 153 da citada lei e sua alteração pela Lei n. 1.438/2011, todo o sistema de seguridade social deve ser guiado, dentre outros, pelos princípios da Eficiência, Universalidade, Solidariedade, Integralidade, Unidade, Obrigatoriedade e Participação Social. Nesse sentido, a base principiológica dos sistemas brasileiro e colombiano é semelhante, ainda que na Colômbia os passos rumo à universalidade e integralidade tenham sido e ainda sejam dados muito mais lentamente, uma vez que envolvem interesses econômicos das EPS.

\footnotetext{
${ }^{6}$ FLEURY Sonia. Universal, dual or plural? Health care models and issues in Latin America. In: MOLINA, Carlos Gerardo; NÚÑEZ DEL ARCO, José (Orgs.). Health services in Latin America and Asia. Washington-D.C.: Interamerican Development Bank; 2001. p. 3-36.

${ }^{7}$ PRADA, C; CHAVES, S. Health system structure and transformations in Colombia between 1990 and 2013 : a socio-historical study. Critical Public Health, v. 28, p. 1-11, 2018. Disponível em: https://www.tandfonline. com/doi/abs/10.1080/09581596.2018.1449943. Acesso em: nov. 2018.

${ }^{8}$ COLOMBIA. Ministerio de la Salud. Orden 19 Sentencia T-760 de 2008. Auto 411 de 2015. Informe II trimestre de 2018. Dirección de Regulación de la Operación del Aseguramiento en Salud, Riesgos Labores y Pensiones. Bogotá D.C., ago. 2018. Disponível em: https://www.minsalud.gov.co/sites/rid/Lists/ BibliotecaDigital/RIDE/DE/DIJ/informe-corte-2-trimestre-2018.pdf. Acesso em: nov. 2018.
} 
O princípio da obrigatoriedade institui, basicamente, que todos os residentes na Colômbia deverão se filiar a um dos três regimes de seguro social em saúde: o regime contributivo, o subsidiado e o especial; os dois primeiros definidos de acordo com a capacidade financeira de cada cidadão e o último, exclusivo para trabalhadores de determinados setores. Assim, enquanto no Brasil vigora um sistema nacional de saúde de finalidade pública, na Colômbia vige o sistema de asseguramento, pautado na filiação obrigatória, na segmentação dos usuários e no contingenciamento da cobertura de serviços 9 .

O regime contributivo é destinado aos trabalhadores inseridos no mercado formal e suas famílias (beneficiários), incluindo-se nesse seguro os trabalhadores liberais e os servidores públicos, os quais têm garantido, por determinação do POS, três níveis de cuidado: básico, intermediário e complexo. O financiamento dessa modalidade se dá pelo pagamento obrigatório de contribuições tanto dos empregados como de seus empregadores.

O regime subsidiado, em contrapartida, visa a dar cobertura à população economicamente vulnerável, ou seja, aquela cuja incapacidade de contribuir é reconhecida pelo Estado por meio do Sistema de Identificación de Beneficiarios. O custeamento desse tipo de cobertura é feito de diferentes formas, entre elas os recursos das esferas governamentais e a captação de uma porcentagem da arrecadação feita no regime contributivo destinada ao Fundo de Solidariedade e Garantia (FOSYGA) - que visa a garantir a compensação entre pessoas de diferentes rendas e riscos, de modo a manter a solidariedade do sistema, haja vista o princípio da solidariedade reger o sistema em questão. Para esses segurados, o POS determinava apenas o primeiro nível de atendimento (básico) e alguns tratamentos mais complexos.

Os regimes Especiais, por sua vez, constituem seguros destinados à cobertura de alguns setores específicos da sociedade, como os funcionários das Forças Armadas, do Judiciário e demais instituições às quais fora dada autonomia para definir seus serviços de saúde.

A população colombiana tem, ainda, a possibilidade de adquirir planos voluntários de saúde, tais como os planos privados no Brasil. Segundo o artigo 37 da Lei n. 1.438/2011, tais serviços complementares poderão ser adquiridos e custeados exclusivamente pelo interessado ou por empresas. No entanto, a adesão a quaisquer desses planos não substitui a filiação obrigatória ao Sistema Geral de Seguridade Social em Saúde.

A descrição dos regimes e da forma de funcionamento da seguridade social no país evidencia o quão complexo é o processo de implementação e eficácia do

${ }^{9}$ LEVINO, Antonio; CARVALHO Eduardo Freese de. Análise comparativa dos sistemas de saúde da tríplice fronteira: Brasil/Colômbia/Peru. Rev Panam Salud Publica, v. 30, n. 5, p. 490-500, 2011. Disponível em: https://www.arca.fiocruz.br/bitstream/icict/28634/2/An\%C3\%A1lise\%20comparativa\%20dos.pdf. 
direito à saúde pela população, dando destaque ao papel dos tribunais para a efetividade das normas colombianas ${ }^{10}$.

Segundo dados de $2011^{11}$, mais de $90 \%$ da população colombiana estava coberta por alguma modalidade de seguro de saúde. Note-se que há uma pequena parcela, ironicamente chamada de "vinculada" (insiders), que ainda não se encontra assegurada, ou seja, encontra-se num limbo operacional por não possuir emprego formal e não ter sido integrada ao regime subsidiado (pessoas não cadastradas no Sistema de Identificación de Beneficiarios de Subsídios do Estado - SISBEN). Essas pessoas têm direito aos serviços oferecidos pelas Secretarias de Saúde, em que predominam programas de prevenção coletiva e cuja responsabilidade geral recai sobre o Ministerio de Salud e Protección Social (MSPS) ${ }^{12}$.

A fim de tornar o sistema mais transparente aos usuários, foram criadas no POS listas que expõem taxativamente os serviços cobertos por determinada modalidade de seguro. Entretanto, quando da implementação do POS, as listas não eram unificadas, ou seja, os serviços ofertados não eram iguais, de modo que os serviços prestados no regime subsidiado correspondiam a cerca de $70 \%$ do contributivo ${ }^{13}$. A intenção era que a diferença entre os regimes fosse temporária, equalizando-se progressivamente os níveis. No entanto, as discrepâncias persistiram ao longo da história e consolidou-se uma realidade absolutamente desigual que só seria repensada em 2008, com a Sentencia T-760 ${ }^{14}$ e com a Ley Estatutaria de Salud (LES), tratadas mais à frente.

\section{O sistema de saúde do Brasil}

Em contrapartida à tendência neoliberal que tanto influenciou a política de saúde na Colômbia, o Brasil introduziu na $\mathrm{CF} / 88$ o direito à saúde como fundamental, universal e integral. Assim, ao invés de diminuir as atribuições do Estado, a CF/88 ampliou a responsabilidade estatal na busca pela efetivação da dignidade humana.

No contexto de redemocratização do país, a partir dos esforços do movimento brasileiro de Reforma Sanitária, ocorreu em 1986 a VIII Conferência Nacional de Saúde, em que foram abertamente debatidas propostas de mudança na área da saúde. Nessa Conferência, foram descritos todos os parâmetros necessários para

\footnotetext{
${ }^{10}$ ARANGO, Rodolfo. op. cit., p. 104-122.

${ }^{11}$ GIOVANELLA, Ligia; FEO, Oscar; FARIA, Mariana; TOBAR, Sebástian (Orgs). Sistemas de salud en Suramérica: desafios para la universalidad la integralidad y la equidade. Instituto Suramericano de Gobierno en Salud. Rio de Janeiro: ISAGS, 2012.

${ }^{12}$ ABADIA, Cesar Ernesto; OVIEDO, Diana G. Bureaucratic itineraries in Colombia. A theoretical and methodological tool to assess managed-care health care systems. Social Science e Medicine, Bogotá, v. 68, n. 6, p. 1153-1160, mar. 2009. http://dx.doi.org/10.1016/j.socscimed.2008.12.049.

${ }^{13}$ LEVINO, Antonio; CARVALHO Eduardo Freese de. op. cit.

${ }^{14}$ COLÔMBIA. Corte Constitucional. Sentencia T-760/08. Disponível em: http://www.corteconstitucional.gov. co/relatoria/2008/t-760-08.htm. Acesso em: 10 set. 2019.
} 
o desenvolvimento de um sistema único dos serviços de saúde no Brasil, erigido sob os princípios de descentralização, integração, regionalização, hierarquização e universalização dos serviços.

A necessidade de reestruturação dos serviços de saúde no Brasil culminou, após a aludida Conferência, na instituição da Comissão Nacional de Reforma Sanitária, que foi a responsável por levar adiante os debates sobre o tema da saúde e propiciar a realização de um projeto de lei que fizesse parte da Constituinte de $1988^{15}$. Assim, como fruto dos esforços do movimento sanitário e de intenso debate, a CF/88 estabeleceu as diretrizes de um Sistema Único de Saúde (SUS), implantado gradualmente pela Lei Orgânica da Saúde (Lei n. 8.080/1990 ${ }^{16}$ ).

Diferentemente do que ocorre na Colômbia, onde os cidadãos pagam diretamente uma taxa de acordo com sua capacidade financeira, o financiamento do SUS provém da receita de impostos e dos orçamentos das três esferas de gestão (União, estados e municípios), ou seja, é financiado por toda a sociedade, de forma direta e indireta, conforme previsto no artigo 195 da CF/88. A Lei n. 8.080/1990 estabelece que os recursos financeiros da Seguridade Social devam ser transferidos, em primeiro lugar, ao Fundo Nacional de Saúde (FNS) e, em segundo lugar, ao Fundo de Saúde dos entes locais (estados e municípios), estando presentes na participação do financiamento ao SUS os três entes estatais (art. 33).

A estruturação política e administrativa do SUS reflete a necessidade de haver no Brasil qualidade e eficiência na prestação dos serviços públicos, como parte de um ideal que, em contraponto a alguns avanços conquistados em quase três décadas de Constituição cidadã, ainda convive com as contradições de um sistema obstaculizado pela falta de planejamento por parte dos poderes públicos, além da insuficiência de recursos e da consequente impossibilidade de universalização do acesso aos serviços públicos de saúde.

Pode-se dizer que é fato que as diretrizes que permearam a criação do SUS como porta primeira de acesso aos serviços de saúde pública ainda não encontraram sua plena efetividade devido às diversas contradições ainda existentes no cerne desse sistema, que não consegue comportar todas as facetas sociais em um país de dimensões continentais como é o Brasil, além dos problemas relacionados aos investimentos em serviços de saúde. Todos esses fatores acarretam a falta e a deficiência na prestação dos serviços de saúde, ocasionando a intensificação da judicialização desse direito após a promulgação da CF/88.

\footnotetext{
${ }^{15}$ ARRETCHE, Marta Teresa da Silva. Estado federativo e políticas sociais: determinantes da descentralização. Rio de Janeiro: Revan; São Paulo: FAPESP, 2000. p. 202.

${ }^{16}$ BRASIL. Lei $n$. 8.080, de 19 de setembro de 1990. Dispõe sobre as condições para a promoção, proteção e recuperação da saúde, a organização e o funcionamento dos serviços correspondentes e dá outras providências. Disponível em: http://www.planalto.gov.br/ccivil_03/leis/I8080.htm. Acesso em: 10 set. 2019.
} 


\section{A judicialização da saúde no Brasil e na Colômbia}

\section{A judicialização da saúde na Colômbia: as ações de tutelas}

A Carta Constitucional colombiana de 1991 incluiu os direitos sociais como serviços públicos, ou seja, de responsabilidade estatal, sem lhes consagrar o status de direito fundamental. No entanto, trouxe importantes instrumentos de acesso à Justiça, através dos quais os cidadãos que tenham qualquer direito cultural, social ou político violado possam exigi-lo frente ao Poder Judiciário. As ações de tutelas, previstas no artigo 86 da Constituição, são o meio legal mais utilizado para tal finalidade, e seu incremento ano a ano revela a ineficácia institucional em garantir a concretização dos direitos sociais à população colombiana.

Segundo dados divulgados pela Defensoría del Pueblo ${ }^{17}$, em 2014 foram propostas 498.240 tutelas, o maior número desde que esse mecanismo foi previsto, em 1991, e que representa um aumento de 9,62\% em relação ao ano anterior. Deste total, mais de $23 \%$, ou seja, cerca de 118 mil ações estão relacionadas ao direito à saúde, número que pode ser ainda maior, tendo em vista que muitos cidadãos também requerem prestações de saúde ao invocar o direito à petição ou à seguridade social. O Gráfico 1 revela a progressão do número de ações de saúde comparado ao total.

Gráfico 1. Progressão do número de ações de saúde na Colômbia

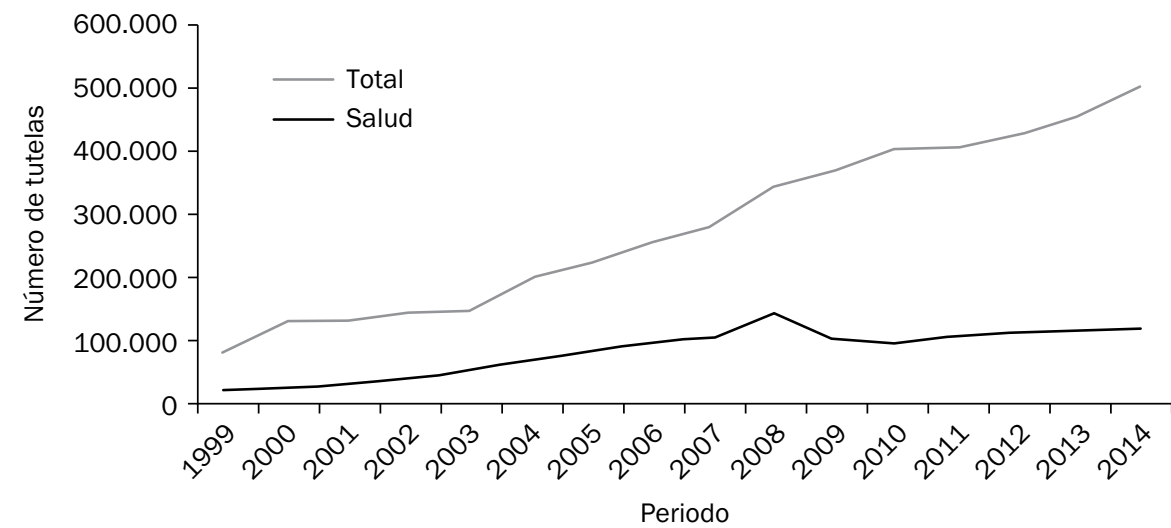

Fonte: Defensoría del Pueblo

${ }^{17}$ COLOMBIA. Defensoría del Pueblo. La tutela y el derecho a la salud. Período 2006-2008. Disponível em: http://www.defensoria.gov.co/public/pdf/LatutelaylosderechosalaSalud.pdf. Acesso em: 03 mar. 2016. 
Desmistificando o argumento de muitos críticos do ativismo judicial, os dados fornecidos pela Defensoría del Pueblo demonstram que o número de tutelas propostas pelos cidadãos do regime contributivo $(48,62 \%$ do total) não é muito maior do que as propostas pelo regime subsidiado (41,70\% do total), desconstruindo o argumento de que o acesso à Justiça seria um privilégio das classes mais abastadas e, portanto, acentuaria as desigualdades já existentes entre os regimes de contribuição e subsidiado ${ }^{18}$.

Quanto à característica de a demanda estar ou não inclusa no POS, ainda é muito elevado o número de tutelas solicitando tratamentos previstos no POS, ou seja, que deveriam ser concedidos imediatamente pelas EPS. Os dados referentes a 2014 demonstram que, no regime contributivo, esse número equivale a $61,70 \%$ das tutelas e no regime subsidiado, a 70,24\%.

A seguir, serão abordadas as mudanças jurisprudenciais e legislativas mais recentes e que têm por finalidade a melhoria do sistema de saúde colombiano.

\section{Sentencia T-760 de 2008 na Colômbia}

A intervenção do Judiciário na saúde colombiana se intensificou com as inovações trazidas pela Constituição de 1991, entre elas a criação da Corte Constitucional e de mecanismos de acesso do cidadão à Justiça, tais como as ações de tutela. Assim como no Brasil, na Colômbia também se instalou forte tensão entre os poderes Executivo, Legislativo e Judiciário, questionando-se qual seria limite da atuação da Corte Constitucional nas políticas públicas de saúde. Segundo Oscar Parra-Vera e Alicia Ely Yamin ${ }^{19}$, nas últimas décadas a ação de tutela tem sido o meio mais utilizado para a proteção do direito à saúde na Colômbia, e a Corte Constitucional ${ }^{20}$ tem consolidado diversas formas de ativismo judicial nessa seara.

Em 2008, o aumento expressivo e constante no número de ações em saúde fez com que a Corte Constitucional tomasse uma importante e polêmica decisão: a Sentencia T-760, de cumprimento imediato e que constituiu um conjunto de determinações dirigidas a todos os envolvidos na prestação do direito à saúde, com o intuito de melhorar a gestão do sistema, garantindo o acesso a serviços de qualidade e, por conseguinte, diminuindo o fluxo de litígios. Ademais, fixou o

\footnotetext{
${ }^{18}$ COLOMBIA. Defensoría del Pueblo. La tutela y el derecho a la salud, cit.

${ }^{19}$ PARRA-VERA, Oscar; YAMIN, Alicia Ely. La Sentencia T-760 de 2008, su implementación y impacto: retos y oportunidades para la justicia dialógica. Disponível em: http://www.corteidh.or.cr/tablas/r32458.pdf. Acesso em: 27 nov. 2017.

${ }^{20}$ A Corte Constitucional foi criada pela Constituição de 7 de julho de 1991 e é responsável por garantir o respeito à integridade da Carta Política, conhecendo de maneira exclusiva sobre os assuntos de constitucionalidade. COLÔMBIA. Corte Constitucional. Disponível em: http://www.corteconstitucional.gov. co/lacorte/. Acesso em: 10 set. 2019.
} 
entendimento de que a saúde não é apenas um serviço público, mas um direito fundamental e autônomo.

A partir da análise de 22 tutelas (ações) e uma ampla base de dados sobre o sistema de saúde, a Corte identificou as principais falhas do sistema e ordenou medidas que visavam a corrigi-las. Entre os diversos pontos atacados pela decisão, pode-se citar a necessidade de atualização periódica dos benefícios inclusos no POS para assegurar o fluxo adequado de recursos financeiros.

A Sentencia T-760 não determinou deveres ilimitados ao Estado; pelo contrário, assinalou que o direito à saúde contém um núcleo essencial que deve ser garantido a toda a população, respeitados os princípios da razoabilidade e proporcionalidade. Desse modo, o órgão reiterou o entendimento no sentido de condicionar a concessão de medicamentos e procedimentos que estivessem fora do POS a critérios como a condição financeira, o mínimo vital do paciente, conforme descrito na decisão, as possibilidades de substituição por insumos mais baratos e a prescrição médica.

A Corte colombiana limitou as demandas que não estejam previstas no (POS), que é a política pública de saúde, mas a indeterminação do termo "mínimo vital" traz grande subjetivismo e impede uma compreensão clara do que está ou não garantido ao cidadão pelo Estado. Tal questão também é causa de embate doutrinário no Brasil, onde os críticos da judicialização apontam que somente o "mínimo existencial" seria de responsabilidade estatal e o que ultrapassar tal limite traria prejuízos ao sistema como um todo e à sociedade. No caso brasileiro, os argumentos contrários à judicialização da saúde tratam sobre a necessidade de se apontar um limite às ações judiciais, em vista dos recursos limitados de que dispõe o Estado para efetivar as políticas de saúde. Esse limite se perfaz tanto na comprovação da hipossuficiência do cidadão quanto na necessidade daquele medicamento ou tratamento solicitado como meio de manutenção à vida com dignidade ${ }^{21}$. $\mathrm{O}$ conceito aqui no Brasil também não é fechado, gerando questionamentos de diversas naturezas e insegurança jurídica.

Apesar da reforma formal do sistema e dos esforços da Corte em emitir dezenas de autos visando ao cumprimento das determinações da Sentencia T-760, o fato é que a realidade material persistiu ineficiente, haja vista os índices de corrupção interna, desvio de recursos e satisfação de interesses alheios ao bem público. Dessa forma, sempre que o governo colombiano insiste em argumentar pela insuficiência de recursos, a Corte evidencia a má gestão, a inconsistência das bases de dados e a ineficácia dos órgãos de controle do sistema.

${ }^{21}$ AZEM, Guilherme Beux Nassif. O direito à saúde e comprovação da hipossuficiência. In: ASSIS, Araken (Coord.). Aspectos polêmicos e atuais dos limites da jurisdição e do direito à saúde. Porto Alegre: Notadez Editora, 2007. 
Desde o advento da Sentencia T-760, a Corte Constitucional da Colômbia, em conjunto com o Ministério da Saúde do país, publicam periodicamente documentos relativos aos resultados provindos desse documento. O último, publicado em 2019, trata das negativas de serviços e tecnologias de saúde públicas para a população (medicamentos, cirurgias e demais serviços), no âmbito das EPS, de forma regional, bem como traz medidas que visam ao aumento da qualidade dos serviços de saúde pública e à diminuição do não fornecimento de serviços à população.

O diferencial trazido em 2018 com relação à qualidade dos serviços de saúde deve-se à implementação de uma ferramenta conhecida como Mi Prescrición (MIPRES, Minha prescrição, em tradução livre), que serviu, segundo o documento, para eliminar os procedimentos de autorização perante o Comitê Técnico Científico, facilitando o acesso aos serviços e procedimentos médicos pelos cidadãos ${ }^{22}$. Outro fato interessante refere-se ao aumento de negativas de acesso aos procedimentos ambulatoriais pelas EPS, mesmo diante de prescrição médica, por conta da burocracia que permeia o sistema de saúde colombiano.

Diante desses dados recentes, vislumbra-se que a dinâmica dos serviços de saúde na Colômbia ainda sobrevive com as marcas da burocratização excessiva da EPS e com a corrupção na área da saúde, o que acarreta a negativa de serviços aos cidadãos.

Assim, apesar dos avanços contrários à mercantilização da saúde, mantiveram-se a segmentação do sistema e a atuação preponderante do setor privado, que segue a lógica de mercado e visa mais ao lucro do que ao bem comum, de modo que persistem as barreiras ao acesso à saúde. Nesse cenário, a negativa administrativa fez com que os pacientes continuassem recorrendo ao Judiciário e impediu que a Sentencia T-760 rompesse com a intensa espiral de judicialização.

\section{Ley Estatutaria de Salud: fim dos paseos de la muerte?}

Em fevereiro de 2015, o presidente Juan Manuel Santos Calderón e o ministro Alejandro Gaviria Uribe sancionaram a Ley Estatutaria de Salud (LES, Lei n. $1.751 / 2015)^{23}$, que converte a saúde em direito fundamental autônomo.

A ley estatutaria na Colômbia é uma norma especial, de hierarquia superior às outras leis. $O$ procedimento para sua aprovação é mais difícil, pois requer o voto favorável da maioria absoluta dos membros do Congresso e precisa ser encerrado

\footnotetext{
${ }^{22}$ O MIPRES é um aplicativo que fortalece a autonomia do profissional de saúde, haja vista que a opinião do médico não mais precisa passar por outra instância, os CTC, para então ser atendida a prescrição e disponibilizado o tratamento, bem como torna mais célere a prestação. Id. Ibid.

${ }^{23}$ COLOMBIA. Ministério de Salud y Protección Social. Ley Estatutaria 1751 de 2015. Regula el derecho fundamental a la salud y se dictan otras disposiciones. Disponivel em: http://www.alcaldiabogota.gov.co/ sisjur/normas/Norma1.jsp?i=60733. Acesso em: 27 nov. 2017.
} 
em uma mesma legislatura. Quando em vigor, a ley estatutaria passa a fazer parte da Constituição, de modo semelhante ao que ocorre com as emendas constitucionais brasileiras.

Até a promulgação da LES, a saúde era considerada apenas um serviço essencial de responsabilidade pública. A elevação à norma fundamental reforça o posicionamento já consolidado pela Corte Constitucional e significa que o direito à saúde agora se encontra acima de qualquer consideração econômica e administrativa, devendo ser garantido a todos igualmente na medida de suas necessidades. Em outras palavras, segundo a lei, os serviços de saúde devem ser contínuos, não podendo ser interrompidos por razões administrativas ou econômicas.

Além disso, o sistema deve convergir para a integralidade das prestações, ou seja, objetiva-se a promoção gradual da ampliação dos benefícios até que consiga atender a todas as necessidades da população, o que fará com que, futuramente, o POS deixe de existir, criando-se apenas uma lista explícita com os serviços não garantidos pelo Estado (como os de natureza estética, os de eficácia não comprovada ou experimentais e os que devem ser prestados no exterior). Isso significa, basicamente, que, se antes os pacientes só tinham direito ao que estava contido no POS, com a nova lei só não terão direito ao que estiver no rol de exclusão.

A LES, além de reconhecer a saúde como direito fundamental e autônomo, traça as diretrizes que devem ser seguidas pelo governo a fim de garantir uma cobertura ampla, integral e includente a toda a população da Colômbia. Mas essas metas têm sido alcançadas pelo poder público ou resultaram em letra morta?

Em 2017, dois anos após a promulgação da LES, alguns apontamentos já puderam ser feitos a respeito da implementação ou não de seus dispositivos. Faz-se a seguir uma curta exposição do que se pode observar atualmente no sistema de saúde colombiano.

A lei dispõe sobre a necessidade de alcançar a integralidade das prestações. Nesse ponto, um dos mecanismos colocados em prática pelo governo para efetivar a previsão foi extinguir os antigos comités técnico-científicos (CTC), que se afiguravam como um entrave burocrático à autorização de tratamentos não inclusos no POS, e inserir o MIPRES.

\subsection{Os paseos de la muerte}

Os paseos de la muerte, ou caminhadas da morte, se iniciam quando uma pessoa se filia a uma Entidade Promotora de Saúde (EPS) que está autorizada pela Superintendência Nacional de Saúde para operar em seu município ou departamento, mas que na realidade não conta com um consultório de atendimento ao usuário nem com uma rede de serviços contratada. No momento da solicitação 
do serviço de saúde, o afiliado a uma EPS perambula por hospitais e clínicas em busca de atendimento médico, o que não acontece por falta de um contrato entre a EPS e o hospital ${ }^{24}$.

Para pôr um fim a essa "caminhada", a estratégia do governo consistiu em impor sanções pecuniárias às EPS, cujo montante em 2015 alcançou 49.800 milhões de pesos. Certamente, a multa é uma alternativa para fazer cumprir a lei, mas talvez não seja a mais eficiente, haja vista que, quando da penalidade, a saúde do paciente já foi há muito violada. Ademais, há de se observar se houve aplicação da penalidade todas as vezes que a lei fora desrespeitada e se a pena foi de fato executada.

No que toca à previsão de elaboração de uma lista contendo as prestações que não serão custeadas pelo sistema, chamada de no-POS, a regulamentação ocorreu no início de 2017 e contém, segundo Ulahy Beltrán Lópes ${ }^{25}$, disposições extremamente complexas, que trazem mais uma preocupação aos usuários do sistema.

Embora pretenda promover mudanças necessárias e que já começam a ocorrer no sistema de saúde colombiano, há inúmeras críticas à LES. Entre elas, cita-se o perigoso desequilíbrio financeiro gerado pelo fim do POS e pela ampliação do direito integral à saúde a todos os colombianos, sem que haja correspondente fonte de custeio. Nesse aspecto, pugna-se por uma transformação real do modelo, criando-se um sistema único devidamente financiado, conforme se observa pela fala de Juan Carlos Giraldo, diretor da Associación de Hospitales y Clínicas: "Se requiere una reforma ordinaria que propugne por un sistema único de salud, financiado de manera suficiente, en el que se reemplace lo inútil del actual esquema y se preserve lo que ha servido".

A maior crítica, porém, é que a reforma não olvidou acabar com um dos maiores problemas do sistema: o enriquecimento das EPS (intermediárias e parasitas de recursos estatais). A forma como o sistema foi estruturado, com a existência das intermediárias, em sua maioria privadas, criou um modelo de seguro que responde aos princípios e às lógicas dos mercados regulados, priorizando o viés financeiro em detrimento da condição de existência do ser humano. ${ }^{27}$

\footnotetext{
${ }^{24}$ VILLADIEGO LORA, Alfredo Enrique. ¿Como evitar el paseo de la muerte? Opinión y Salud. Disponível em: https://www.opinionysalud.com/evitar-paseo-la-muerte/. Acesso em: 28 nov. 2017.

${ }^{25}$ BELTRAN LOPES, Ulahy. Dos años después de la ley estatutaria de salud: ¿igual o mejor? Disponível em: http://ulahybeltranlopez.blogspot.com.br/2017/02/dos-anos-despues-de-la-ley-estatutaria_21.html. Acesso em: 28 nov. 2017.

${ }^{26}$ FERNANDES, Carlos Francisco. Con fuertes desafíos, comienza en Colombia era de salud como derecho. El Tiempo, 16 feb. 2017. Disponível em: http://www.eltiempo.com/archivo/documento/CMS-16821511. Acesso em: 28 nov. 2017.

${ }^{27}$ JIMÉNEZ, Wilson Giovanni et al. Ley estatutaria: ¿avance hacia la garantía del derecho fundamental a la salud? Rev Colomb Cir., n. 31, p. 81-90, 2016 Disponível em: http://www.scielo.org.co/pdf/rcci/v31n2/ v31n2a2.pdf. Acesso em: 28 nov. 2017.
} 


\section{A Judicialização da saúde no Brasil}

O direito à saúde no Brasil é universal e deve ser garantido pelo Estado por meio de políticas sociais e econômicas que visem à garantia plena desse direito para todos os cidadãos brasileiros. No entanto, assim como na Colômbia, há uma crise de gestão e controle do sistema de saúde, impedindo que este atue de forma eficaz.

Nesse contexto de incapacidade do poder público para atender às demandas sociais e de expressa previsão normativa dos direitos sociais fundamentais é que o direito à saúde no Brasil deixou de ser uma preocupação das instâncias tradicionais - Executivo e Legislativo - e passou a importar ao Poder Judiciário, que tem como missão garantir a concretização da Carta Maior $^{28}$.

Desde a década de 1990 até esta década de 2010, a judicialização da saúde no Brasil vem se tornando cada vez mais expressiva. Segundo relatório emitido pela Consultoria Jurídica do Ministério da Saúde, a União sofreu, entre 2009 e 2011, um aumento de $22 \%$ referente ao direcionamento de ações judiciais, o que representa um total de 10.486 (2009) e 12.811 (2011) processos, respectivamente. Deve ser levado em consideração também que, na maioria das ações judiciais, ao lado da União figuram os respectivos entes estaduais e municipais, que acabam por atender a demanda, o que retira o dispêndio de recursos por parte do ente federal. Nesse caso, os estados e municípios foram responsáveis, dentro do total apresentado, pelo atendimento de 1.782 solicitações em 2009 e de 1.931 em $2011^{29}$.

Junto com o crescimento das ações judiciais que efetivamente demandaram aquisições provindas do Ministério da Saúde, houve também um aumento de quase $300 \%$ no gasto total com procedimentos cirúrgicos e equipamentos médicos requeridos junto ao Judiciário, ou seja, passando de $\mathrm{R} \$ 83,1$ milhões em 2009 para R\$243,9 milhões em $2011^{30}$.

A maior parte das ações judiciais em direito à saúde versa sobre assistência farmacêutica - o fornecimento de medicamentos e insumos -, o que denota o caráter extremamente curativo das demandas, conforme Gráfico 2, elaborado pelo Ministério da Saúde.

\footnotetext{
${ }^{28}$ BARROSO, Luís Roberto. Judicialização, ativismo judicial e legitimidade democrática. (Syn)thesis, v. 5, n. 1, p. 23-32, 2012. Disponível em: http://www.epublicacoes.uerj.br/ojs/index.php/synthesis/article/ view/7433/5388. Acesso em: abr. 2015.

${ }^{29}$ INSTITUTO DE DIREITO SANITÁRIO APLICADO - IDISA. Medicamentos excepcionais e prioridades de saúde no Brasil. Disponível em: http://www.idisa.org.br/site/documento_4062_0_medicamentos-excepcionaise-prioridades-de-saude-no-brasil.html. Acesso em: jan. 2016. p. 139-156.

${ }^{30}$ Id. Ibid.
} 
Gráfico 2. Evolução dos gastos com medicamentos em demandas judiciais, Ministério da Saúde, Brasil

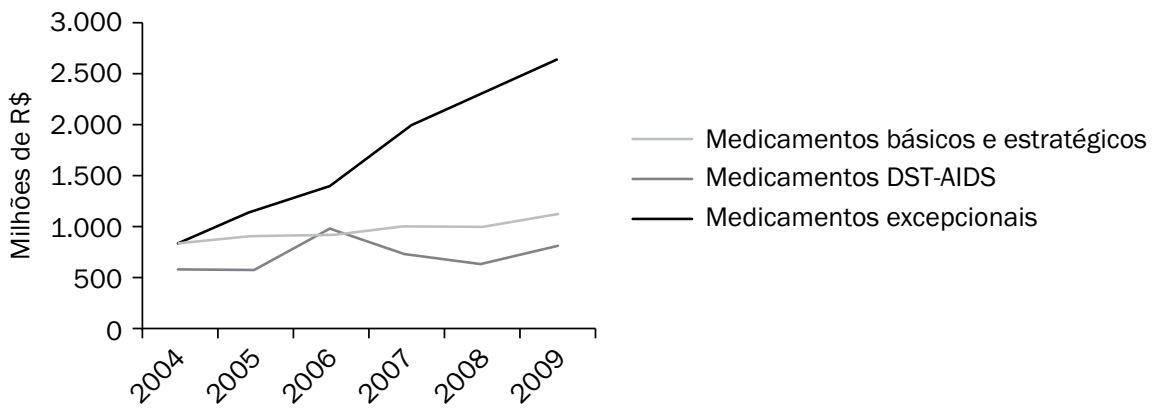

Fonte: IDISA - Instituto de Direito Sanitário Aplicado ${ }^{31}$.

De acordo com o Gráfico 2, é possível vislumbrar a quantidade de recursos públicos que foram aplicados no atendimento a decisões judiciais versando sobre o fornecimento de medicamentos no Brasil. Verifica-se que, ao longo dos anos, o fenômeno foi se intensificando cada vez mais e o Brasil sofreu com o maior número de ações judiciais nessa área, suscitando inúmeras questões de ordem política e judiciária, principalmente no que atina à gestão do sistema de saúde e ao sistema de repasse e aplicação de verbas pelos entes federativos no SUS.

A fim de mapear as causas e experiências dos tribunais na judicialização da saúde, o Conselho Nacional de Justiça (CNJ) produziu em 2015 um relatório decorrente da pesquisa intitulada "Judicialização da saúde no Brasil: dados e experiências"32.

Nessa pesquisa, foram constatadas algumas características em comum nas ações judiciais de saúde em todos os tribunais do Brasil, sendo elas: (i) foco curativo das demandas - as ações versam em sua maioria sobre o fornecimento e a garantia de medicamentos, tratamentos, próteses etc.; (ii) predominância da litigação individual; (iii) tendência a deferimento final e antecipação de tutela, pois pode-se dizer que $99 \%$ das ações têm caráter de urgência; (iv) pouca menção, nas decisões judiciais, à audiência pública do Supremo Tribunal Federal (STF) que, em 2009, procurou levantar questões para buscar soluções à judicialização da saúde no Brasil (o que será tratado com maior detalhes no tópico a seguir); (v) pouca menção às contribuições do CNJ nas decisões judiciais, especialmente no que se

\footnotetext{
${ }^{31}$ INSTITUTO DE DIREITO SANITÁRIO APLICADO - IDISA. Medicamentos excepcionais e prioridades de saúde no Brasil, cit.

${ }^{32}$ ASENSI, Felipe Dutra; PINHEIRO, Roseni (coord.). Judicialização da saúde no Brasil: dados e experiências. Brasília: Conselho Nacional de Justiça, 2015.
} 
refere às Recomendações n. $31 / 2010^{33}$ e n. $36 / 2011^{34}$, que trazem parâmetros para a atuação do Judiciário na judicialização da saúde; (vi) pouca menção ao Fórum Nacional da Saúde e aos comitês estaduais de saúde, que trazem inúmeros estudos sobre o fenômeno no Brasil, de grande contribuição para a comunidade jurídica; (vii) tendência à utilização do Núcleo de Assistência Técnica (NAT), implantado a partir das discussões da audiência pública sobre a judicialização da saúde em 2009 do STF, especialmente nas capitais, apesar de não haver qualquer menção à função dos NAT nas decisões judiciais, vez que se afiguram como uma estratégia para a atividade judicante em saúde ${ }^{35}$.

Comparando os dados brasileiros com os dados colombianos, verifica-se que, em ambos os países, a judicialização é um fenômeno presente e intenso, que gera conflitos entre os poderes estatais constituídos, dado que a presença do Judiciário no âmbito político sempre é vista como indevida e malversada.

A ineficiência ou inexistência de políticas públicas de saúde, somada à instabilidade entre os poderes, é um entrave à promoção universal e integral da saúde. Fato é que a falta de harmonia e cooperação entre Judiciário, Legislativo e Executivo reflete-se na camada social que necessita dos serviços públicos e não tem sua situação contemplada pelo modelo de gestão taxativo do Sistema Único de Saúde.

\section{A audiência pública sobre a judicialização da saúde em 2009 no STF}

Com o aumento exponencial do fenômeno da judicialização da saúde, o então presidente do STF, ministro Gilmar Mendes, convocou em 2009 uma audiência pública para que fossem discutidas soluções e alternativas atinentes ao direito à saúde, tendo como intuito:

[...] ouvir o depoimento de pessoas com experiência e autoridade em matéria de Sistema Único de Saúde, objetivando esclarecer as questões técnicas, científicas, administrativas, políticas, econômicas e jurídicas relativas às ações de prestação de saúde ${ }^{36}$.

\footnotetext{
${ }^{33}$ BRASIL. Conselho Nacional de Justiça. Recomendação n. 31, de 30 de março de 2010. Recomenda aos Tribunais a adoção de medidas visando a melhor subsidiar os magistrados e demais operadores do direito, para assegurar maior eficiência na solução das demandas judiciais envolvendo a assistência à saúde. Disponivel em: http://www.cnj.jus.br/atos-normativos?documento=877. Acesso em: 10 set. 2019.

${ }^{34}$ BRASIL. Conselho Nacional de Justiça. Recomendação n. 36, de 12 de julho de 2011. Recomenda aos Tribunais a adoção de medidas visando a melhor subsidiar os magistrados e demais operadores do direito, com vistas a assegurar maior eficiência na solução das demandas judiciais envolvendo a assistência à saúde suplementar. Disponível em: http://www.cnj.jus.br/busca-atos-adm?documento=1227. Acesso em: 10 set. 2019.

${ }^{35}$ JUDICIALIZAÇÃO da saúde no Brasil: dados e experiências. Coord. Felipe Dutra Asensi e Roseni Pinheiro. Brasília-DF: Conselho Nacional de Justiça, 2015. Disponível em: https://www.cnj.jus.br/files/conteudo/ destaques/arquivo/2015/06/6781486daef02bc6ec8c1e491a565006.pdf.

${ }^{36}$ SUPREMO TRIBUNAL FEDERAL - STF. Despacho convocatório de audiência pública de 5 de março de 2009. Disponivel em: http://www.stf.jus.br/arquivo/cms/processoAudienciaPublicaSaude/anexo/Despacho_ Convocatorio.pdf. Acesso em: 13 maio 2017.
} 
A audiência pública deixou evidentes diversas propostas que visam a contornar as causas e os efeitos da judicialização, sendo que duas foram as mais citadas: o "aprimoramento das instâncias regulatórias no Brasil, seja ao que se refere à concessão de registro para acesso ao mercado brasileiro, seja pela incorporação de tecnologias no âmbito do SUS"; e a necessidade de o "Judiciário levar em consideração os Protocolos Clínicos e as Diretrizes Terapêuticas (PCDT) do Ministério da Saúde, os quais devem ser atualizados periodicamente" ${ }^{37}$.

Outras propostas também chamaram a atenção, como o fornecimento de assessoria técnica ao Judiciário, por meio da criação dos Núcleos de Assessoria Técnica (NAT), que devem oferecer consultoria aos magistrados a fim de assessorá-los em suas decisões, e alternativas relativas à escassez de recursos financeiros na saúde pública ${ }^{38}$.

O resultado dessa audiência pública foi observado nos anos que se seguiram, com a providência de algumas medidas que representaram avanços na área da saúde, como a Lei n. $12.401 / 2011^{39}$, que trata sobre a assistência terapêutica e a incorporação de tecnologia em saúde no SUS, e a Lei Complementar n. 141/2012 ${ }^{40}$, que regulamentou a Emenda Constitucional n. 29/2000 ${ }^{41}$, referente à aplicação mínima de recursos financeiros pelos entes federativos nos serviços de saúde pública. Destacam-se, ainda, a Recomendação n. 31/2010 e a Resolução n. 107/2010 ${ }^{42}$, ambas do CNJ. A primeira trouxe medidas que os tribunais deveriam adotar a fim de reduzir o número de demandas judiciais em saúde, e a segunda instituiu o Fórum da Saúde, para monitoramento de tais ações.

${ }^{37}$ GOMES, Dalila F. et al. Judicialização da saúde e a audiência pública convocada pelo Supremo Tribunal Federal em 2009: o que mudou de lá para cá? Saúde Debate, Rio de janeiro, v. 38, n. 100, p. 139-156, jan./mar. 2014. Disponível em: http://www.scielo.br/pdf/sdeb/v38n100/0103-1104-sdeb-38-100-0139. pdf. Acesso em 27 nov. 2017.

${ }^{38}$ Id. Ibid., p.150-151.

${ }^{39}$ BRASIL. Lei $n$. 12.401, de 28 de abril de 2011. Altera a Lei $n^{\circ} 8.080$, de 19 de setembro de 1990, para dispor sobre a assistência terapêutica e a incorporação de tecnologia em saúde no âmbito do Sistema Único de Saúde - SUS. Disponível em: http://www.planalto.gov.br/ccivil_03/_Ato2011-2014/2011/Lei/ L12401.htm. Acesso em: 10 set. 2019.

${ }^{40}$ BRASIL. Lei Complementar n. 141, de 13 de janeiro de 2012. Regulamenta o $\S 3^{\circ}$ do art. 198 da Constituição Federal para dispor sobre os valores mínimos a serem aplicados anualmente pela União, Estados, Distrito Federal e Municípios em ações e serviços públicos de saúde; estabelece os critérios de rateio dos recursos de transferências para a saúde e as normas de fiscalização, avaliação e controle das despesas com saúde nas 3 (três) esferas de governo; revoga dispositivos das Leis nos 8.080 , de 19 de setembro de 1990, e 8.689, de 27 de julho de 1993; e dá outras providências. Disponível em: http://www. planalto.gov.br/ccivil_03/leis/LCP/Lcp141.htm. Acesso em: 10 set. 2019.

${ }^{41}$ BRASIL. Emenda Constitucional n. 29, de 13 de setembro de 2000. Altera os arts. 34, 35, 156, $160,167 \mathrm{e}$ 198 da Constituição Federal e acrescenta artigo ao Ato das Disposições Constitucionais Transitórias, para assegurar os recursos mínimos para o financiamento das ações e serviços públicos de saúde. Disponível em: http://www.planalto.gov.br/ccivil_03/constituicao/Emendas/Emc/emc29.htm. Acesso em: 10 set. 2019.

${ }^{42}$ BRASIL. Conselho Nacional de Justiça. Resolução n. 107, de 06 de abril de 2010. Institui o Fórum Nacional do Judiciário para monitoramento e resolução das demandas de assistência à saúde. Disponível em: https://www.cnj.jus.br/atos-normativos?documento=173. Acesso em: 10 set. 2019. 
Por outro lado, ficou mais do que evidente que as políticas de saúde apresentam falhas no que tange à aplicação e concretização dos princípios do SUS e que, por conta dessas falhas, os usuários passaram a ver no Judiciário um meio efetivo de garantia, e não um meio excepcional de pleitear o direito. Além disso, não se observou a elaboração de uma lei de responsabilidade sanitária, que configuraria um importante instrumento contra a má-gestão nos serviços públicos de saúde.

Em vista dos dados aqui apresentados referentes ao Brasil, verifica-se que um dos grandes desafios no país é a diminuição das ações judiciais e o estudo de estratégias que visem a contornar o fenômeno da judicialização da saúde, vez que o SUS, em alguns estados brasileiros, apresenta índices extremamente negativos - $\mathrm{o}$ que denota um sistema cuja gestão precisa de reestruturação e de uma articulação maior entre os entes federativos.

A conclusão a que se chega, ao analisar o fenômeno da judicialização da saúde no Brasil, é a de que o SUS é uma via de duas pistas: há um caminho para a utilização dos serviços, com acesso limitado pelos recursos já disponíveis; e outro para obtenção de acesso irrestrito garantido por ações judiciais. Esse problema poderia ser amenizado por uma gestão pública eficiente, voltada aos interesses dos usuários, e pela correta aplicação dos recursos públicos destinados à saúde.

\section{Considerações finais}

Levando em consideração os sistemas de saúde no Brasil e na Colômbia, tem-se, de início, que ambos são frutos de um sistema político que fomenta a desigualdade social e, por consequência, gera a descrença da população nas instituições políticas - fato este comprovado pela intensificação do ajuizamento de ações judiciais que visam à garantia forçada do direito à saúde pelo poder público.

A análise comparada dos sistemas brasileiro e colombiano de saúde permite traçar algumas diferenças, principalmente no que se refere a sua estruturação, conforme maior ou menor influência da política neoliberal. O modelo colombiano, chamado de pluralismo estruturado, apesar de recentemente ter tornado a saúde um direito fundamental e guiar seu sistema pelo princípio da universalidade, coloca a execução e a gestão do direito à saúde a cargo de empresas privadas (especialmente as Entidades Promotoras de Saúde), que tão somente enxergam o lucro possível, deixando a população ao alvedrio de um sistema cheio de falhas estruturais.

Já no caso brasileiro, apesar das inúmeras falhas estruturais e das contradições internas do SUS, observa-se que a responsabilidade pelo acesso aos serviços de saúde é exclusivamente do poder público, que deve garanti-lo de forma plena e irrestrita, devendo os hospitais privados ser fiscalizados pelo Estado, de acordo com as disposições constitucionais previstas na $\mathrm{CF} / 88$. 
Quanto à progressão do número de ações judiciais em saúde, pode-se notar que, apesar dos esforços para reduzi-los - como a Sentencia T-760 na Colômbia e as inúmeras estratégias no Brasil -, ambos os países se encontram mergulhados num contexto de intenso ativismo judicial, que só tende a aumentar.

Após a análise dos sistemas aqui estudados, chega-se à conclusão de que é impossível garantir o direito à saúde por meio de um sistema cheio de entraves e contradições internas, que impedem que o usuário acesse os serviços de forma plena e irrestrita. Certo é que, além de padecerem de uma reestruturação em sua gestão pública - de forma a desburocratizar e voltar os olhos aos usuários, visando à satisfação dos serviços -, os dois sistemas necessitam de uma aplicação intensa de recursos financeiros a fim de abarcar todos os casos, ou pelo menos a maioria deles, que porventura possam aparecer no âmbito da saúde.

\section{Referências}

ABADIA, Cesar Ernesto; OVIEDO, Diana G. Bureaucratic itineraries in Colombia. A theoretical and methodological tool to assess managed-care health care systems. Social Science e Medicine, Bogotá, v. 68, n. 6, p. 1153-1160, mar. 2009. http://dx.doi.org/10.1016/j. socscimed.2008.12.049.

ARANGO, Rodolfo. Promoción de los derechos sociales constitucionales por via de protección judicial. El Outro Derecho, ILSA, Bogotá-D.C., Colombia, n. 28, jul. p. 104-122, 2002. Disponível em: https://s3.amazonaws.com/academia.edu.documents/34888817/ PROMOCION_D_ELOS_DERECHOS_SOCIALES_CONSTITUCIONALES.pdf?AWS AccessKeyId=AKIAIWOWYYGZ2Y53UL3A\&Expires $=1541515415 \&$ Signature $=$ K6b $\% 2$ BPyVSbTf1poOPkDMwcNwPUgY\%3D\&response-content-disposition=inline\%3B\%20filename\%3DPromocion_de_los_derechos_sociales_const.pdf. Acesso em: fev. 2017.

ARRETCHE, Marta Teresa da Silva. Estado federativo e políticas sociais: determinantes da descentralização. Rio de Janeiro: Revan; São Paulo: FAPESP, 2000.

ASENSI, Felipe Dutra; PINHEIRO, Roseni (coord.). Judicialização da saúde no Brasil: dados e experiências. Brasília: Conselho Nacional de Justiça, 2015.

AZEM, Guilherme Beux Nassif. O direito à saúde e comprovação da hipossuficiência. In: ASSIS, Araken (Coord.). Aspectos polêmicos e atuais dos limites da jurisdição e do direito à saúde. Porto Alegre: Notadez Editora, 2007.

BARROSO, Luís Roberto. Judicialização, ativismo judicial e legitimidade democrática. (Syn) thesis, v. 5, n. 1, p. 23-32, 2012. Disponível em: http://www.epublicacoes.uerj.br/ojs/index. php/synthesis/article/view/7433/5388. Acesso em: abr. 2015.

BELTRAN LOPES, Ulahy. Dos años después de la ley estatutaria de salud: ¿igual o mejor? Disponível em: http://ulahybeltranlopez.blogspot.com.br/2017/02/dos-anos-despues-de-laley-estatutaria_21.html. Acesso em: 28 nov. 2017. 
COLÔMBIA. Corte Constitucional. Disponível em: http://www.corteconstitucional.gov.co/ lacorte/. Acesso en: 10 set. 2019.

COLÔMBIA. Defensoría del Pueblo. La tutela y el derecho a la salud. Período 2006-2008. Disponível em: http://www.defensoria.gov.co/public/pdf/LatutelaylosderechosalaSalud.pdf. Acesso em: 03 mar. 2016.

COLÔMBIA. Ministerio de la Salud. Orden 19 Sentencia T-760 de 2008. Auto 411 de 2015. Informe II trimestre de 2018. Dirección de Regulación de la Operación del Aseguramiento en Salud, Riesgos Labores y Pensiones. Bogotá D.C., ago. 2018. Disponível em: https:// www.minsalud.gov.co/sites/rid/Lists/BibliotecaDigital/RIDE/DE/DIJ/informe-corte-2trimestre-2018.pdf. Acesso em: nov. 2018.

FERNANDES, Carlos Francisco. Con fuertes desafíos, comienza en Colombia era de salud como derecho. El Tiempo, 16 feb. 2017. Disponível em: http://www.eltiempo.com/archivo/ documento/CMS-16821511. Acesso em: 28 nov. 2017.

FLEURY Sonia. Universal, dual or plural? Health care models and issues in Latin America. In: MOLINA, Carlos Gerardo; NÚÑEZ DEL ARCO, José (Orgs.). Health services in Latin America and Asia. Washington-D.C.: Interamerican Development Bank; 2001. p. 3-36.

GIOVANELLA, Ligia; FEO, Oscar; FARIA, Mariana; TOBAR, Sebástian (Orgs). Sistemas de salud en Suramérica: desafios para la universalidad la integralidad y la equidade. Instituto Suramericano de Gobierno en Salud. Rio de Janeiro: ISAGS, 2012.

GOMES, Dalila F. et al. Judicialização da saúde e a audiência pública convocada pelo Supremo Tribunal Federal em 2009: o que mudou de lá para cá? Saúde Debate, Rio de janeiro, v. 38, n. 100, p. 139-156, jan./mar. 2014. Disponível em: http://www.scielo.br/pdf/sdeb/v38n100/01031104-sdeb-38-100-0139.pdf. Acesso em 27 nov. 2017.

INSTITUTO DE DIREITO SANITÁRIO APLICADO - IDISA. Medicamentos excepcionais e prioridades de saúde no Brasil. Disponível em: http://www.idisa.org.br/site/documento_4062_0_ medicamentos-excepcionais-e-prioridades-de-saude-no-brasil.html. Acesso em: jan. 2016.

JIMÉNEZ, Wilson Giovanni et al. Ley estatutaria: ¿avance hacia la garantía del derecho fundamental a la salud? Rev Colomb Cir., n. 31, p. 81-90, 2016 Disponível em: http://www. scielo.org.co/pdf/rcci/v31n2/v31n2a2.pdf. Acesso em: 28 nov. 2017.

JUDICIALIZAÇÃO da saúde no Brasil: dados e experiências. Coord. Felipe Dutra Asensi e Roseni Pinheiro. Brasília-DF: Conselho Nacional de Justiça, 2015. Disponível em: https:// www.cnj.jus.br/files/conteudo/destaques/arquivo/2015/06/6781486daef02bc6ec8c1e49 1a565006.pdf.

LEVINO, Antonio; CARVALHO Eduardo Freese de. Análise comparativa dos sistemas de saúde da tríplice fronteira: Brasil/Colômbia/Peru. Rev Panam Salud Publica, v. 30, n. 5, p. 490-500, 2011. Disponível em: https://www.arca.fiocruz.br/bitstream/icict/28634/2/ An\%C3\%A1lise\%20comparativa\%20dos.pdf. 
ORGANIZAÇÃO DAS NAÇÕES UNIDAS - ONU. Assembleia Geral das Nações Unidas. Constituição da Organização Mundial da Saúde (OMS/WHO) - 1946. Disponível em: http:// www.direitoshumanos.usp.br/index.php/OMS-Organiza\%C3\%A7\%C3\%A3o-Mundial-daSa\%C3\%BAde/constituicao-da-organizacao-mundial-da-saude-omswho.html. Acesso em: jan. 2016.

PAIVA, Carlos Henrique Assunção; TEIXEIRA, Luiz Antonio. Reforma sanitária e a criação do Sistema Único de Saúde: notas sobre contextos e autores. História, Ciências, Saúde, Manguinhos, Rio de Janeiro, v. 21, n. 1, p. 15-35, jan./mar. 2014. Disponível em: http://www. scielo.br/pdf/hcsm/v21n1/0104-5970-hcsm-21-1-00015.pdf. Acesso em: dez. 2015.

PARRA-VERA, Oscar; YAMIN, Alicia Ely. La Sentencia T-760 de 2008, su implementación y impacto: retos y oportunidades para la justicia dialógica. Disponível em: http://www.corteidh. or.cr/tablas/r32458.pdf. Acesso em: 27 nov. 2017.

PRADA, C; CHAVES, S. Health system structure and transformations in Colombia between 1990 and 2013: a socio-historical study. Critical Public Health, v. 28, p. 1-11, 2018. Disponível em: https://www.tandfonline.com/doi/abs/10.1080/09581596.2018.1449943. Acesso em: nov. 2018.

VILLADIEGO LORA, Alfredo Enrique. ¿Como evitar el paseo de la muerte? Opinión y Salud. Disponível em: https://www.opinionysalud.com/evitar-paseo-la-muerte/. Acesso em: 28 nov. 2017.

Fernanda de Castro Nakamura - Doutoranda em Serviço Social pela Universidade Estadual Paulista Júlio de Mesquita Filho - Campus Franca (Unesp/Franca); mestrado em Planejamento e Análise de Políticas Públicas pela Unesp/Franca. Advogada. São Paulo/SP, Brasil. E-mail: fernandanakamuraadv@gmail.com

Nathália Melazi Caobianco - Bacharel em Direito pela Universidade Estadual Paulista Júlio de Mesquita Filho - Campus Franca (Unesp/Franca). Advogada. São Paulo/SP. Brasil. 